\title{
Pseudo winging and snapping of scapula due to sub scapular osteochondroma-a rare case report
}

\author{
Surojit Mondal ${ }^{1}$, Aniket Chowdhury ${ }^{2}$, Ranadeb Bandyopadhyay ${ }^{3}$, Debdutta \\ Chatterjee ${ }^{4}$, Rakesh Kumar ${ }^{5}$ Eashin $\mathrm{Gazi}^{6}$, Subrata $\mathrm{Pal}^{7}$ \\ Department of Orthopaedics, B.S.Medical College, West Bengal,India ${ }^{1,3,4}$ \\ Department of Community Medicine, B.S.Medical College, West Bengal,India ${ }^{2,5,6}$ \\ Department of Pathology, B.S.Medical College, West Bengal,India ${ }^{7}$
}

\begin{abstract}
Osteochondroma or exostosis is most common primary benign bone tumor and comprising of more than one third of primary bone tumor. Osteochondroma originate mainly from the metaphysis of long bone with more than $35 \%$ of cases affecting the bone around the knee and seldom found in flat bones like scapula, that may cause abnormal scapulothoracic movement leading to pain, snapping scapula and pseudowinging of scapula. This article present a novel case of Osteochondroma on ventral aspect of scapula in a 12 years old in an otherwise healthy male causing pseudo winging and snapping of scapula and occasional pain in affected area. X-ray demonstrated a cauliflower like exophytic mass on ventral aspect of right scapula. Computed Tomography and Magnetic Resonance Imaging showed an abnormal bony mass arising from scapula. Surgical en block resection was performed and patient symptoms resolved dramatically. The histopathological diagnosis was osteochondroma. So in a patient with winging and snapping of scapula one should be aware of rare diagnosis osteochondroma along with other more common aetiology.
\end{abstract}

Keywords: Osteochondroma, Scapula, Snapping Scapula, Pseudo Winging

\section{Introduction}

Osteochondroma most common primary bone tumor usually occurring near the end of long bone .Osteochondroma may be solitary (90\%) or multiple in the form of hereditary multiple exostosis (HME) in about $10 \%$ of cases ${ }^{1}$. Most of the osteochondroma are asymptomatic depending on their size and location. Osteochondroma originate frequently from end of long bone and rarely involves flat bone such as scapula and spine. ${ }^{1,2}$, Winging of scapula is defined as prominence of medial border or vertebral border of scapula ${ }^{(3,4,5)}$. It clinically presents decreased range of active shoulder movement, upper girdle muscular weakness pain or cosmetic changes may observe. The classic etiology of winging of scapula is serratus anterior muscle impairment secondary to long thoracic nerve palsy. However bone, muscle, various nerve and shoulder joint pathology may be associated with winging of scapula ${ }^{(6,7,8)}$.Tumor of scapula such as Osteochondroma rarely associated with winging of scapula. ventral Osteochondroma of scapula may lead to snapping scapula, pain full crepitus and pseudo winging and mass effect due to bursa formation. ${ }^{(3,4,5)}$. This article report a 12 yrs boy presented with snapping, winging of his right scapula as a result of scapular Osteochondroma treated with en block surgical excision.

\section{Case report}

12 yrs old, right hand dominant, school student presented in our orthopedic clinic complaining a painful crepitus of the right shoulder. He also complains of audible and palpable grating sensation of 3 month duration prior to his presentation there was no antecedent history of trauma and fever .Other sibling were normal.

Physical examination revealed a healthy boy with full active range of movement of his right shoulder. A grating sensation arouse from his right scapulothoracic region with movement.The vertebral border of right scapula was more prominent than left. (Fig1).Winging of right scapula was clear at rest also. Winging was not increased as patient pushing the arm against the wall (Fig2) .Muscle strength, Deep Tendon Reflexes and the result of sensory examination were all normal. There were no overlying skin changes or erythema and non mobile mass was non tender on palpation. Plain radiograph and Computed Tomogram revealed a large bony protuberance on ventral aspect of right scapula about $3 * 5 \mathrm{~cm}$ in measurement (Fig 3,4). Magnetic Resonance Imaging revealed this mass was extending anteriorly and medially against the ribs and had a characteristic mushroom shaped appearance with some marrow signal centrally with no obvious soft tissue component. A diagnosis of ventral scapular exostosis is made and patient was offered for surgical treatment.

Preoperative laboratory evaluation revealed white blood cell count, differential count, Erythrocyte Sedimentation Rate $(9 \mathrm{~mm} / \mathrm{hr})$,C-Reactive protein $(<0.65 \mathrm{mg} / \mathrm{dl})$ within normal limit. Surgical en block excision 
was performed under general anesthesia in prone position. The shoulder was rotated internally ,thereby lifting the medial border of scapula away from thoracic cage. The approach was dorsally based parallel to medial border of scapula .Trapezius muscle was split in line with its fiber. The Rhomboideus major and Levator scapulae muscles were detached .The scapula was retracted from the chest wall subperiosteally. A mushroom shaped mass measured $3.5^{*} 6$ was excised from the costal surface of scapula. No bursa was demonstrated .grossly no malignant transformation wasnoticedin cartilaginouscap

Microscopy show neoplasm composed of bony trabeculae intervened mostly by fatty tissue and bony marrow. The chondrocyte revealed columnar deposition with minimal pleomorphism. The cartilaginous cap was relatively hypo cellular and chondrocyte were small and unremarkable. Other pertinent were negative including absence of "bluebone" bizarre metaplastic cartilage or marked cytological atypia. Overall the histological feature diagnostic of Osteochondroma. (Fig6)

The arm was immobilized in sling for four weeks and during this period only pendulum exercise was allowed. After four weeks this patient was sends to a physiotherapist for appropriate rehabilitation programme. He felt no abnormal movement in six week post operative follow up and his symptoms resolved dramatically.

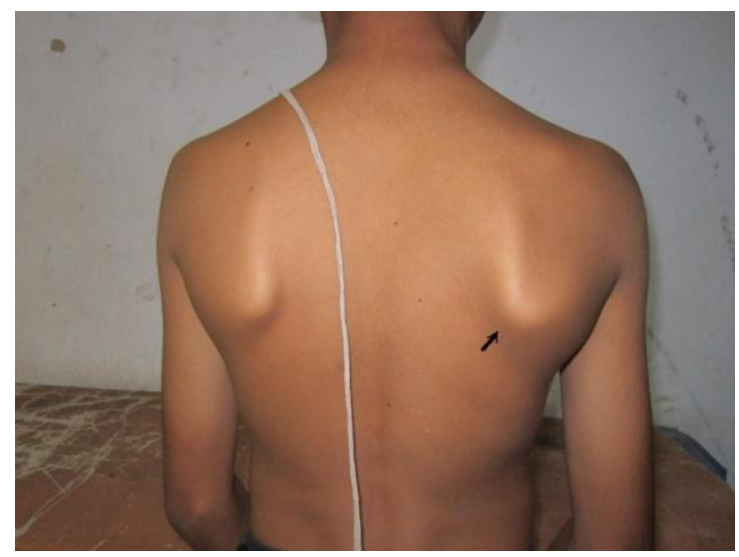

Fig 1 Clinical photograph shows pseudo winging of the right scapula

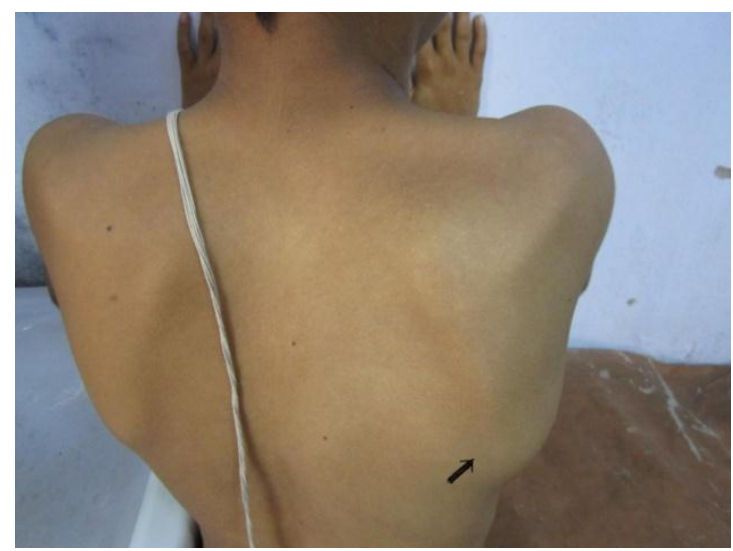

Fig 2 revealed Winging was not increased as patient pushing the arm against the wall

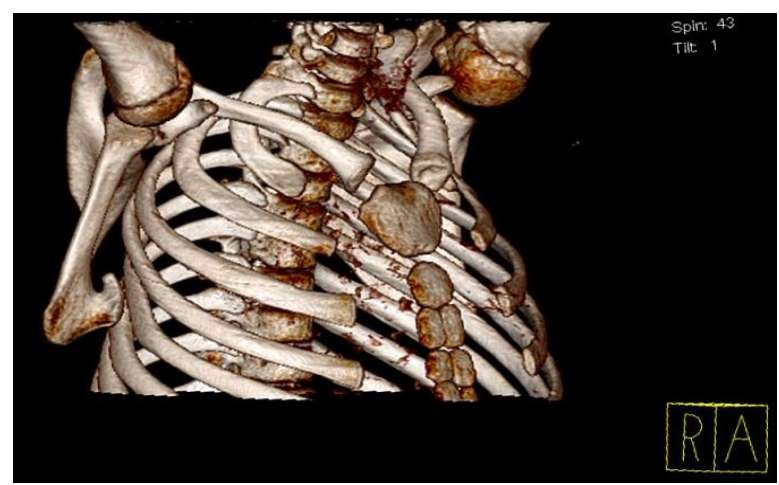

Fig3 Computed Tomogram revealed a large bony protuberance on ventral aspect of inferior angle of right scapula (from anterolateral side) 


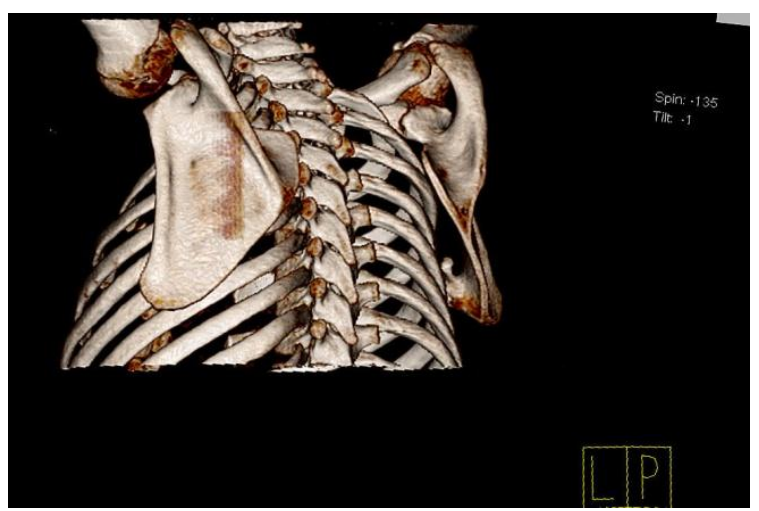

Fig 4 Computed Tomogram revealed a large bony protuberance on ventral aspect of inferior angle of right scapula (from posterior side)

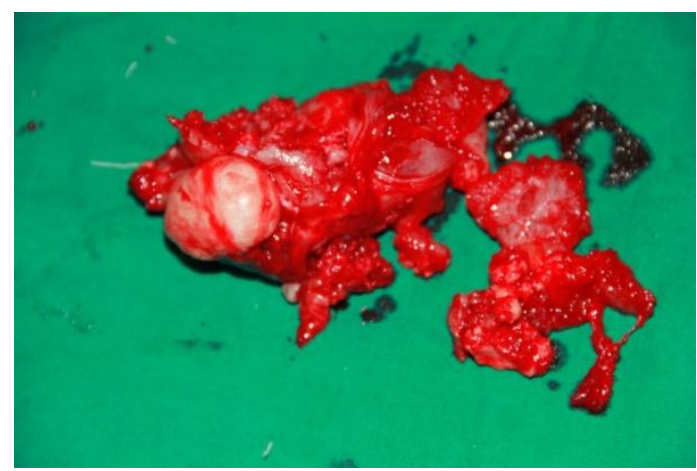

Fig 5 revealed large cartilage capped exostosis removed from ventral aspect of scapula

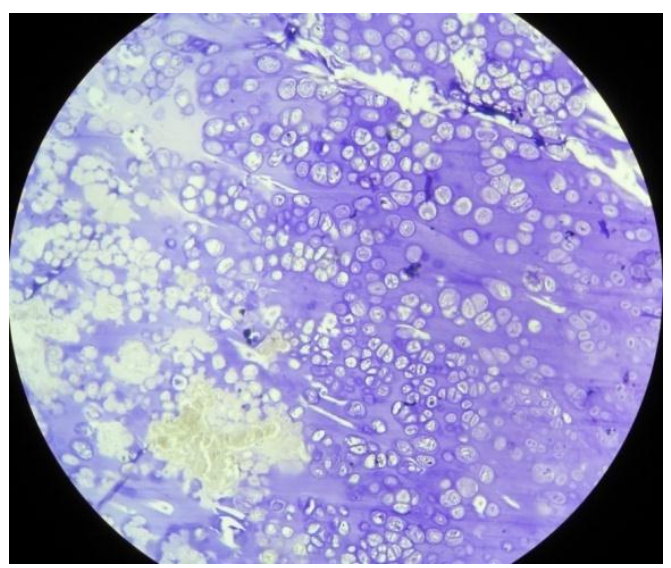

Fig 6 show neoplasm composed of bony trabeculae intervened mostly by fatty tissue and bony marrow. The chondrocyte revealed columnar deposition with minimal pleomorphism.

\section{Discussion}

The snapping scapula syndrome was first described by Boinet in 1867. Since then, case reports of

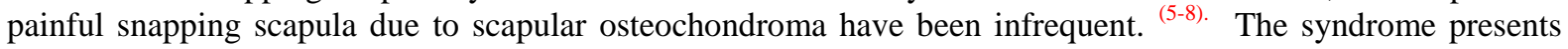
with pain in back and around the shoulder girdle with audible and/or palpable crepitus of scapula on scapulothoracic movement. Milch described this crepitus as a tactile-acoustic phenomenon secondary to an abnormality between the anterior surface of scapula and the thoracic wall. ${ }^{(10)}$ Milch also reported that Mauclaire divided the sounds into three classes-Froissement or gentle friction sound, Frottement or somewhat louder sound and Craquement or loudsnapping sound. According to Milch, the second category is the commonest. ${ }^{10}$. Although most sub scapular Osteochondroma are frequently associated with a snapping or grating sensation in the shoulder region, ${ }^{13-19}$ some of the patients reported were associated with winging or pseudo winging of the scapula. ${ }^{8,17}$

Though winging of the scapula is generally considered to be synonymous with serratus anterior palsy. ${ }^{8,13,14}$ There are many causes other than serratus anterior palsy of winging of the scapula. A number of these cases have been described as pseudowinging. ${ }^{13,14}$ 
Winging of the scapula can be either dynamic or static. ${ }^{6,7,8}$ Dynamic winging is due to neuromuscular disorders and because of the resulting muscular imbalance. The deformity is produced by active and resisted shoulder movements and is often absent at rest. Static winging is due to a fixed deformity in the shoulder girdle, spine, or ribs and is characteristically present at rest with the arm at the side. Active or resisted shoulder movements do not increase the deformity. Solitary exostosis or osteochondroma of the underside of the scapula may produce static winging. ${ }^{6,7,8}$ Osteochondroma is the most common primary benign tumor of the scapula with an incidence of $3 \%-4.6 \%,{ }^{6,10}$ Usually, it is a single lesion located on the anterior side of the scapular body. Surgical resection of the tumor is the treatment of choice for osteochondroma. ${ }^{13,14,15,17,19,20}$. The Osteochondroma in this case report expanded the deep surface of the right scapula, showing the scapula away from the chest wall and producing static winging. Total surgical resection was performed. Scapular Osteochondroma causes snapping usually in adolescence or early adulthood ${ }^{11}$ This "pseudo-winging" is indicative of a sub scapular mass with neurologically intact serratus anterior ${ }^{21}$ The Osteochondroma in this case report expanded the deep surface of the right scapula, showing the scapula away from the chest wall and producing static winging. Total surgical resection was performed

\section{Conclusion}

To conclude, snapping scapula syndrome is a disorder caused by abnormal scapulothoracic motion of variable etiology. This syndrome may be a clinical manifestation of a sub scapular Osteochondroma. Surgical resection of the tumors is a reliable treatment which results in resolution of the crepitus and pain.

\section{References}

[1] Edelman RR, Hesselink JR, Zlatkin MB. Vol. 3. Philadelphia: Saunders Elsevier; 2006. Clinical magnetic resonance imaging. pp. 2320-27.

[2] Hassankhani EG. Solitary lower lumbar osteochondroma (spinous process of L3 involvement): a case report. Cases J. 2009;2:9359

[3] Aalderink K, Wolf B. Scapular osteochondroma treated with arighthroscopic excision using prone positioning. Am J Orighthop2010; 39(2): E11-E14.

[4] Lazar MA, Kwon YW, Rokito AS. Snapping scapula syndrome. J Bone Joint Surg 2009;91A (9): 2251-2262

[5] Okada K, Terada K, Sashi R et al. Largebursa formation associated with osteochondroma of the scapula: a case reporight and review of the literature. Jpn J ClinOncol 1999; 29(7): 256-260.

[6] Bloch AM, Nevo Y, Ben-Sira L, Harel S, Shahar E. Winging of the scapula in a child

[7] Danielson LG, el-Haddad I. Winged scapuladue to osteochondroma. Reporightof 3 children.ActaOrighthop Scand. 1989; 60:728729.

[8] Fiddian NJ, King RJ. The winged scapula.ClinOrighthop. 1984; 185:228-236.

[9] Carlson HL, Haig AJ, Stewaright DC. Snapping scapula syndrome: Threecase reporights and analysis of the literature. Arch Phys Med Rehabil. May. 1997;78:506-511

[10] Milch H. Parightialscapulectomy for snapping of the scapula. J Bone Joint. Surg Am. 1950; 32:561-566

[11] Parsons TA. The snapping scapula and sub scapularexostosis. J Bone Joint Surg Am. May 1973; 55B:345-349

[12] Strizak AM, Cowen MH. The snapping scapula syndrome. A case reporight. J Bone Joint Surg Am. Jul 1982;64:941-942

[13] Cooley LH, Torg JS. "Pseudowinging" of thescapula secondary to sub scapularosteochondroma.ClinOrighthop. 1982; 162:119-124.

[14] Lynch AF, Fogarighty EE, Dowling FE, ReganBF. Pseudowinging of the scapula due toosteochondromata. J PediatrOrighthop. $1985 ; 5: 722-724$.

[15] Kumar N, Ramakrishnan V, Johnson GV, Southern S. Endoscopically-assisted excision of scapular osteochondroma. ActaOrighthopScand. 1999; 70:394-396

[16] Milch H. Parightialscapulectomy for snappingof the scapula. J Bone Joint Surg Am. 1950;32-A:561-566

[17] Parsons TA. The snapping scapula and sub scapular exostosis. J Bone Joint Surg Br.1973; 55:345-349.

[18] Strizak AM, Cowen MH. The snappingscapula syndrome. A case reporight. J BoneJointSurg Am. 1982; 64:941-942.

[19] Blacksin MF, Benevenia J. Neoplasm of thescapula. AJR Am J Roentgenol. 2000;174:1729-1735.

[20] Nercessian O, Denton JR. Carightilaginousexostosis arising from the ventral surface of the scapula. A case reporight. Clin Orighthop.1988; 236:145-147.

[21] Mohsen MS, Moosa NK, Kumar P. Osteochondroma of the scapula associated with winging and large bursa formation. Med Prin Pract. Surg Am. 1950;32:561-5662006;15:387-390 